\begin{tabular}{ll|l}
\cline { 2 - 3 } & \multicolumn{2}{l}{ Intervent Neurol 2016;5:131-139 } \\
\cline { 2 - 3 } & $\begin{array}{l}\text { DOI: 10.1159/000446853 2016 S. Karger AG, Basel } \\
\text { Published online: June 17, 2016 }\end{array}$ & $\begin{array}{l}\text { 1664-9737/16/0054-0131\$39.50/0 } \\
\text { www.karger.com/ine }\end{array}$ \\
\hline
\end{tabular}

\title{
Visual Improvement after Intra-Arterial Thrombolysis for Central Retinal Artery Occlusion Does Not Correlate with Time to Treatment
}

\author{
Paul S. Page ${ }^{a} \quad$ Alexander C. Cambon $^{b}$ Robert F. James ${ }^{a}$ \\ ${ }^{a}$ Department of Neurological Surgery, University of Louisville School of Medicine, and \\ ${ }^{b}$ Department of Bioinformatics and Biostatistics, University of Louisville School of Public \\ Health and Information Sciences, Louisville, Ky., USA
}

\section{Key Words}

Central retinal artery occlusion · Fibrinolysis · Infusions · Intra-arterial thrombolysis ·

Therapeutic thrombolysis - Time to treatment

\begin{abstract}
Background: Intra-arterial thrombolysis (IAT) for the treatment of acute central retinal artery occlusion (CRAO) has demonstrated variable results for improving visual acuity and remains controversial. Despite limited evidence, time from symptom onset to thrombolysis is believed to be an important factor in predicting visual improvement after IAT. Methods: A comprehensive review of the literature was conducted and individual subject level data were extracted from relevant studies. From these, a secondary analysis was performed. Initial and final logarithm of the minimum angle of resolution (logMAR) scores were either abstracted directly from relevant studies or converted from provided Snellen chart scores. Change in logMAR scores was used to determine overall treatment efficacy. Results: Data on 118 patients undergoing IAT from five studies were evaluated. Median logMAR improvement in visual acuity was -0.400 ( $p<0.001)$. There was no significant association between logMAR change and time to treatment when time (hours) was described as a continuous variable or described categorically $[0-4,4-8,8-12,12+h$; or $0-6,6-12,12+h]$. Conclusion: The visual improvement observed in this series had no relationship to the time from symptom onset to treatment with IAT. This suggests that patients may have the possibility for improvement even with delayed presentation to the neurointerventionalist. Other factors, such as completeness of retinal occlusion, may be more important than time to treatment. Additional studies to determine optimal patient selection criteria for the endovascular treatment of acute CRAO are needed.
\end{abstract}




\section{Introduction}

Central retinal artery occlusion (CRAO) is a rare ophthalmologic emergency that may ultimately result in complete vision loss of the affected eye. Despite the historic use of noninvasive standard therapies in the treatment of acute nonarteritic CRAO, recent studies have demonstrated little advantage to their use compared with the natural disease course [1-3]. Research into the utilization of thrombolytic therapy for the treatment of CRAO has been ongoing for over 20 years and has included intravenous and intra-arterial routes of administration $[4,5]$. Though the intravenous use is less invasive, the use of intra-arterial thrombolysis (IAT) by selective catheterization of the ophthalmic artery ostia with a microcatheter has garnered interest due to its ability to minimize systemic complications and theoretically increase the time to treatment therapeutic window.

Retina is neural tissue, thereby allowing CRAO to be pathophysiologically compared to acute ischemic stroke (AIS). Unlike in AIS, the benefit in outcomes associated with minimizing time from symptom onset to revascularization has not been firmly established for CRAO [6]. Animal models have demonstrated that irreversible retinal ischemia may occur in as little as 105 min after total occlusion [7]. While many experts agree that a temporal relationship between revascularization and visual outcomes most likely exists, studies have inconsistently demonstrated this relationship. Concerns exist regarding the quality of a negative previous randomized controlled trial designed to assess the efficacy of IAT where the times to thrombolysis were significantly greater than what would be acceptable in the treatment of AIS [8]. In this study, we performed a systematic literature review of IAT treatment for CRAO and extracted individual subject level data to analyze the relationship between improvement in visual acuity outcomes and time to treatment in the existing literature. Through this method, we provide the largest study ever conducted examining the effect of time to thrombolysis on visual outcomes after CRAO.

\section{Methods}

A comprehensive literature search was conducted in MEDLINE and EMBASE for studies utilizing IAT in the treatment of CRAO. MEDLINE and EMBASE were searched from January 1, 1946 to January 1, 2015. Key words included 'retinal artery', 'intra-arterial fibrinolysis', 'intra-arterial thrombolysis', and 'intraarterial thrombolytic'. Each title was subsequently reviewed for relevance and only English language studies were evaluated. Additionally, the reference section of each study was reviewed to identify additional relevant studies that may have been missed with the initial search. We avoided duplication of patient data by examining authors with multiple published studies evaluating CRAO patients. We selected data from their newest study to avoid the possibility that a prior publication may have contained a smaller series of an older subset of the same patients. Inclusion criteria consisted of acute-onset nonarteritic CRAO; IAT with either urokinase (FDA off-label) or recombinant tissue plasminogen activator (FDA off-label), and studies containing individual patient data on initial visual acuity, final visual acuity, and time from symptom onset to treatment. From these studies, logarithm of the minimum angle of resolution (logMAR) scores were either abstracted directly from provided data or converted from Snellen chart scores that had been provided. Lower logMAR scores represent better visual acuity. Values for profoundly low visual acuity scores were subsequently converted to a logMAR scale in accordance with the technique described by Lange et al. [9]. Mercier et al. [10] included a profoundly low visual acuity choice of 'see steady hand' that was not quantified by Lange et al. A logMAR score equal to 2.13 was chosen to quantify this option as it represented a profoundly low visual acuity ranging between counting fingers (logMAR $=1.98)$ and hand movement $(\log M A R=2.28)$.

A Wilcoxon signed rank test was performed on initial and final logMAR scores to evaluate for treatment efficacy. A nonparametric ANOVA and linear regression analysis were conducted to evaluate the relationship between time to thrombolysis and change in visual outcomes. Intervals for distinct ANOVAs included: [0-4, 


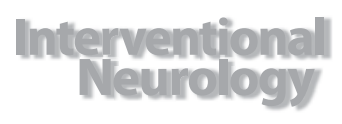

\begin{tabular}{l|l}
\hline Intervent Neurol 2016;5:131-139 \\
\hline DOI: 10.1159/000446853 & $\begin{array}{l}\text { ( 2)16 S. Karger AG, Basel } \\
\text { www.karger.com/ine }\end{array}$ \\
\hline
\end{tabular}

Page et al.: Visual Improvement after Intra-Arterial Thrombolysis for Central Retinal

Artery Occlusion Does Not Correlate with Time to Treatment

Table 1. Studies fulfilling all inclusion criteria

\begin{tabular}{|c|c|c|c|c|c|c|}
\hline $\begin{array}{l}\text { First author } \\
\text { [Ref.], year }\end{array}$ & Study type & $\begin{array}{l}\text { Total } \\
\text { patients }\end{array}$ & $\begin{array}{l}\text { Average time } \\
\text { from symptom } \\
\text { onset to } \\
\text { treatment, h }\end{array}$ & Agent & $\begin{array}{l}\text { Timing of post IAT } \\
\text { BCVA examination }\end{array}$ & $\begin{array}{l}\text { Coexisting arterial } \\
\text { occlusions }\end{array}$ \\
\hline $\begin{array}{l}\text { Mercier [10], } \\
2014\end{array}$ & $\begin{array}{l}\text { Retrospective } \\
\text { case series }\end{array}$ & 14 & $\begin{array}{l}8.0 \\
{[4.5-17.0]}\end{array}$ & $\begin{array}{l}\text { tPA } \\
\text { Mean: } 35 \text { mg, SD } 13\end{array}$ & 6-12 months & None specified \\
\hline $\begin{array}{l}\text { Pettersen [11], } \\
2005\end{array}$ & $\begin{array}{l}\text { Retrospective } \\
\text { case series }\end{array}$ & 6 & $\begin{array}{l}9.7 \\
{[6.0-18.0]}\end{array}$ & $\begin{array}{l}\text { tPA } \\
\text { Range: } 10-30 \mathrm{mg}\end{array}$ & 2 days to 2.5 years & None specified \\
\hline $\begin{array}{l}\text { Butz [12], } \\
2003\end{array}$ & $\begin{array}{l}\text { Retrospective } \\
\text { case series }\end{array}$ & 22 & $\begin{array}{l}7.6 \\
{[4.0-11.0]}\end{array}$ & $\begin{array}{l}\text { Urokinase } \\
\text { Mean: } 642,000, \text { SD } 300 \mathrm{~K} \\
\text { OR } \\
\text { tPA } \\
\text { Mean: } 27 \mathrm{mg}, \text { SD } 8\end{array}$ & Not specified & $\begin{array}{l}\text { Severe ICA stenosis (1) } \\
\text { ICA occlusion (1) }\end{array}$ \\
\hline $\begin{array}{l}\text { Richard [13], } \\
1999\end{array}$ & $\begin{array}{l}\text { Retrospective } \\
\text { case series }\end{array}$ & 53 & $\begin{array}{l}14.0 \\
{[3.0-50.0]}\end{array}$ & $\begin{array}{l}\text { tPA } \\
\text { Maximum: } 40 \mathrm{mg}\end{array}$ & 3 months & None specified \\
\hline $\begin{array}{l}\text { Schumacher } \\
{[14], 1993}\end{array}$ & $\begin{array}{l}\text { Retrospective } \\
\text { case series }\end{array}$ & 23 & $\begin{array}{l}15.4 \\
{[3.833-60.0]}\end{array}$ & $\begin{array}{l}\text { Urokinase } \\
\text { Maximum: } 1.2 \text { million units } \\
\text { OR } \\
\text { tPA } \\
\text { Maximum: } 70 \mathrm{mg}\end{array}$ & $\begin{array}{l}\text { Immediately to } \\
6 \text { months }\end{array}$ & $\begin{array}{l}\text { ICA occlusion (4) } \\
\text { ICA stenosis (4) } \\
\text { MCA occlusion (1) }\end{array}$ \\
\hline
\end{tabular}

$\mathrm{BCVA}=$ Best corrected visual acuity; $\mathrm{tPA}=$ tissue plasminogen activator; $\mathrm{K}=$ thousand; $\mathrm{ICA}=$ internal carotid artery.

$4-8,8-12,12+\mathrm{h}]$ and $[0-6,6-12,12+\mathrm{h}]$. A linear regression analysis was conducted to assess the correlation between time (hours) and change in logMAR. Both natural $\log$ and $\log _{10}$ transformations were utilized to assess for existence of correlation. A p value cutoff of 0.05 was used to determine statistical significance for all data analyses. All statistical analyses were performed in SAS, version 9.3.

\section{Results}

The comprehensive literature search produced five studies satisfying all inclusion criteria. The study publication dates ranged from 1992 to 2013 and subject level data were obtained for 118 patients (table 1) [10-14]. Another study conducted by Framme et al. [15] was also identified; however, due to a language barrier, it was omitted from this study. While other relevant studies were identified, these did not include patient level data and thus were not included in our analysis [16-20]. Of the patients examined, 75.7\% (87/118) were male with an average age of 63.2 years (SD 14.1). The mean and median time from symptom onset to IAT was 12.4 h (SD 10.4) and 9 h (IQR 6.9-12), respectively. Fibrinolytic agents utilized included recombinant tissue plasminogen activator in 93 patients and urokinase in 25 patients.

Initial visual acuity assessment demonstrated that $73.8 \%$ of patients presented with a visual acuity logMAR score of 2.0 or worse. After IAT treatment, this improved dramatically to $39.8 \%$ having a visual acuity of 2.0 or worse. Additionally, only $10.9 \%$ of patients had an initial visual acuity of $<1.0$ on presenting assessment; however, this improved to $28.8 \%$ after IAT (fig. 1). Mean logMAR improvement for all patients studied was -0.61 (SD 0.68). A ShapiroWilk normality test demonstrated that logMAR scores were not normally distributed $(\mathrm{p}<$ $0.0001)$. A Wilcoxon signed rank test was subsequently conducted demonstrating a significant median improvement in visual acuity of -0.400 (IQR $0-1.06) \operatorname{logMAR}(\mathrm{p}<0.001)$. 


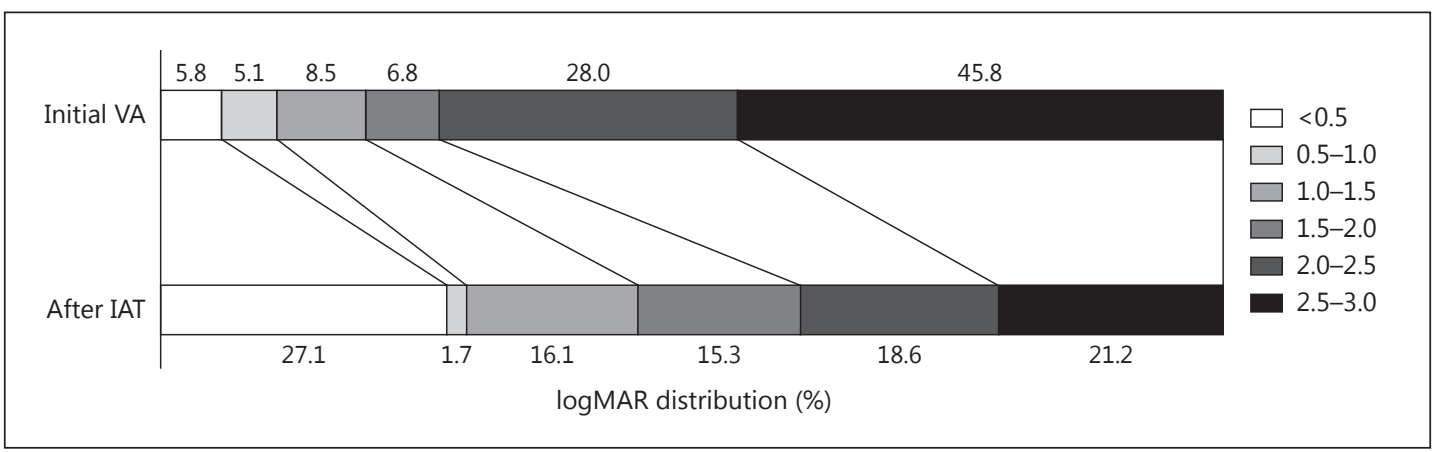

Fig. 1. Shift diagram demonstrating initial and final logMAR score distributional improvement in visual acuity (VA).

Fig. 2. Scatter plot and fit for regression of change in logMAR with hours to treatment $\left(\log _{10}\right.$ scale). Data points represent individual patient improvement in $\log$ MAR $(\mathrm{n}=118)$. Improvement in $\log$ MAR score represents improvement in visual acuity.

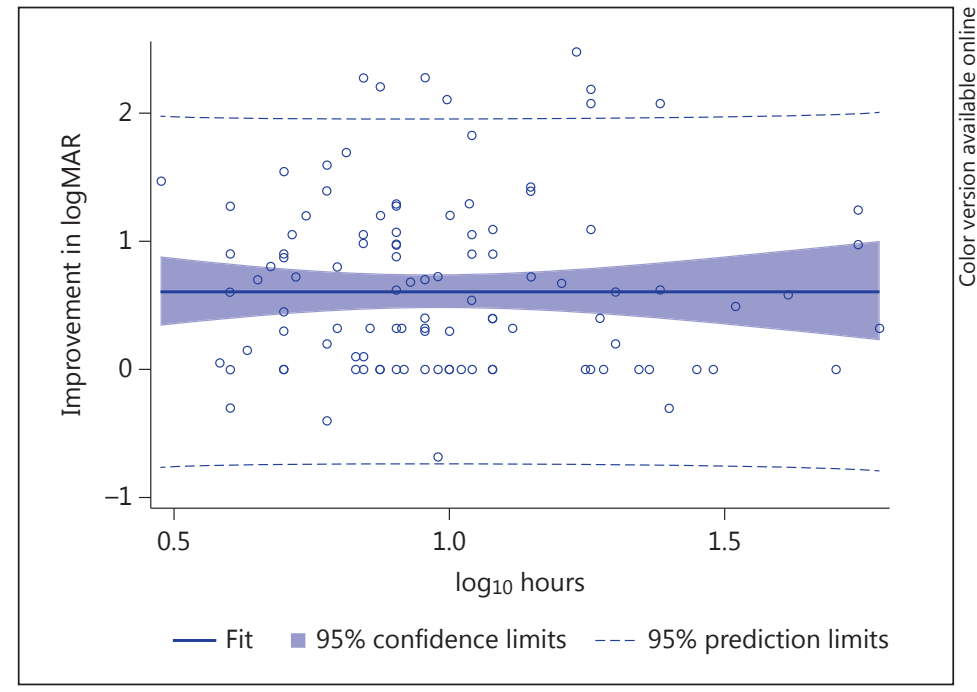

A scatter plot of individual patients' improvement in $\log$ MAR versus $\log _{10}$ hours from symptom onset to treatment is provided in figure 2 . Linear regression analysis results demonstrated no significant correlation between time to thrombolysis and improvement in logMAR using either natural $\log$ or $\log _{10}$ transformations for hours $\left(\mathrm{p}=0.99, \mathrm{R}^{2}=0\right.$ for each). For the purpose of exploratory analysis, two ordinal intervals were examined including $[0-4,4-8$, $8-12,12+]$ (table 2) and $[0-6,6-12,12+]$ (table 3) hour intervals. Mean change in logMAR was found to be largest in the $12+$-hour time interval, with an improvement of -0.700 logMAR. The smallest mean improvement in logMAR occurred in the 8- to 12-hour time interval $(-0.484)$ (fig. 3). Nonparametric ANOVA demonstrated no temporal relationship with change in $\log$ MAR for the $[0-4,4-8,8-12,12+]$ or $[0-6,6-12,12+]$ hour intervals examined $(\mathrm{p}=$ $0.546, \mathrm{~F}=0.71$ and $\mathrm{p}=0.721, \mathrm{~F}=0.33$, respectively).

Complications were observed in 11 of the cases examined (9.3\%). Seven thromboembolic complications were noted including 2 occurring during catheter manipulation, 3 transient ischemic events, 1 minor stroke, and 1 major stroke. Of these ischemic events, 6 resolved in the same session with use of IAT. Other complications included 1 intracranial hemorrhage, 1 femoral artery access hematoma, and 1 hypertensive crisis. In 1 case, the patient experienced pain on urokinase injection, which quickly resolved. Long-term morbidity occurred in 1 case resulting from a major stroke. 


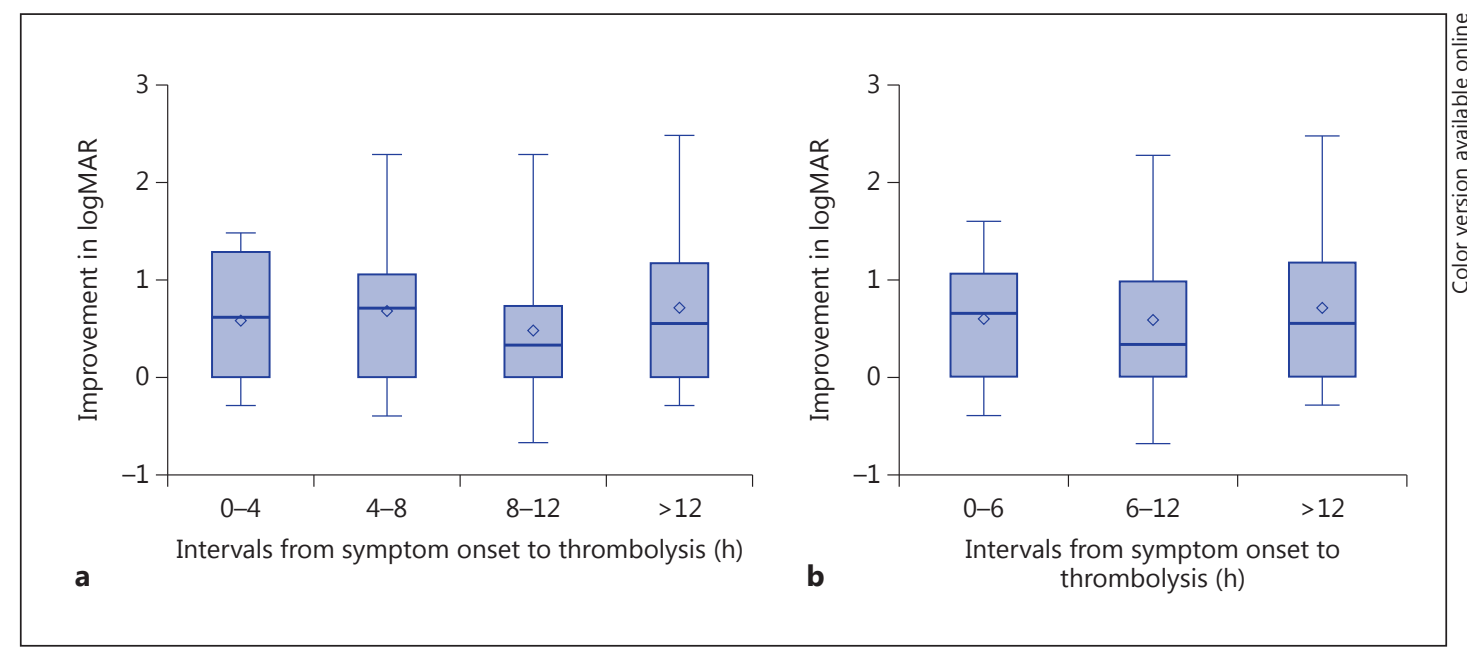

Fig. 3. Standard box plots of logMAR distributions among 4-hour (a) and 6-hour (b) time intervals demonstrating no significant difference in logMAR distribution between groups.

Table 2. ANOVA of change in logMAR and 4-hour time intervals

\begin{tabular}{|c|c|c|c|c|c|}
\hline \multirow[t]{2}{*}{ Change in logMAR } & \multicolumn{5}{|l|}{ 4-Hour intervals } \\
\hline & $\begin{array}{l}\text { total } \\
(\mathrm{n}=118)\end{array}$ & $\begin{array}{l}0-4 \\
(n=7)\end{array}$ & $\begin{array}{l}4-8 \\
(n=45)\end{array}$ & $\begin{array}{l}8-12 \\
(n=38)\end{array}$ & $\begin{array}{l}>12 \\
(n=28)\end{array}$ \\
\hline Mean $(95 \% \mathrm{CI})$ & $\begin{array}{l}-0.610 \\
(-0.732,-0.489)\end{array}$ & $\begin{array}{l}-0.572 \\
(-1.077,-0.068)\end{array}$ & $\begin{array}{l}-0.667 \\
(-0.855,-0.479)\end{array}$ & $\begin{array}{l}-0.484 \\
(-0.686,-0.283)\end{array}$ & $\begin{array}{l}-0.700 \\
(-0.988,-0.412)\end{array}$ \\
\hline Median (min, max) & $\begin{array}{l}-0.400 \\
(-2.478,0.680)\end{array}$ & $\begin{array}{l}-0.602 \\
(-1.475,0.301)\end{array}$ & $\begin{array}{l}-0.700 \\
(-2.280,0.400)\end{array}$ & $\begin{array}{l}-0.359 \\
(-2.280,0.680)\end{array}$ & $\begin{array}{l}-0.538 \\
(-2.478,0.301)\end{array}$ \\
\hline
\end{tabular}

Change in logMAR equals follow-up minus initial. Larger absolute value negative numbers equal greater visual improvement; larger absolute value positive numbers equal greater visual worsening. $p=0.546$.

Table 3. ANOVA of change in logMAR and 6-hour time intervals

\begin{tabular}{lllll}
\hline Change in logMAR & \multicolumn{2}{l}{ 6-Hour intervals } & & \\
\cline { 2 - 5 } & $\begin{array}{l}\text { total } \\
(\mathrm{n}=118)\end{array}$ & $\begin{array}{l}0-6 \\
(\mathrm{n}=26)\end{array}$ & $\begin{array}{l}6-12 \\
(\mathrm{n}=64)\end{array}$ & $\begin{array}{l}>12 \\
(\mathrm{n}=28)\end{array}$ \\
\hline Mean $(95 \% \mathrm{CI})$ & -0.610 & -0.577 & -0.605 & -0.700 \\
& $(-0.732,-0.489)$ & $(-0.809,-0.346)$ & $(-0.767,-0.443)$ & $(-0.988,-0.412)$ \\
\hline Median (min , max) & -0.400 & -0.651 & -0.320 & -0.538 \\
& $(-2.478,0.680)$ & $(-1.600,0.400)$ & $(-2.280,0.680)$ & $(-2.478,0.301)$ \\
\hline
\end{tabular}

Change in logMAR equals follow-up minus initial. Larger absolute value negative numbers equal greater visual improvement; larger absolute value positive numbers equal greater visual worsening. $\mathrm{p}=0.721$ 
Page et al.: Visual Improvement after Intra-Arterial Thrombolysis for Central Retinal Artery Occlusion Does Not Correlate with Time to Treatment

\section{Discussion}

The prognosis of CRAO is considered dismal, with some studies reporting as few as $8 \%$ experiencing a recovery in visual acuity with the use of noninvasive (conservative) standard therapy [16]. While research into the use of IAT for the treatment of CRAO has been ongoing for over 20 years, results continue to be highly variable and there is no consensus on its efficacy. Though many controlled cohort studies have demonstrated a significantimprovement in visual acuity after IAT, these publications likely suffer from patient selection bias. Likewise, the overall literature likely suffers from publication bias in favor of IAT therapy as negative studies tend not to be submitted and/or selected for publication. A single recent randomized clinical trial by Schumacher etal.[19] (EAGLE study) demonstrated no significantimprovement in visual outcomes after IAT compared with those treated with conservative therapy [16-19]. Due to this variability in the existing literature, determination of the optimal patient selection criteria for IAT that may allow for the demonstration of efficacy in randomized controlled trials is an active area of investigation. Influences including time from symptom onset to fibrinolysis and degree of arterial occlusion and dosing regimen are being explored as potential major factors that may correlate with final visual outcomes after IAT. Time to thrombolysis has inconsistently been demonstrated to have an influence on visual outcomes in existing studies; however, expert opinion appears to strongly favor it playing a prominent role in final visual acuity after IAT due to the similarities between CRAO and AIS $[8,12,18]$.

In our study, a pooled population of 118 patients representing five separate studies demonstrated a significant improvement in visual acuity after treatment with IAT. Due to the typical selection and publication bias mentioned above, the overall improvement with IAT seen in this study represents a weak level of evidence supporting IAT, and it is not the focus of this study. The key finding of this study is that in this subset of patients who happen to have an overall significant visual improvement after IAT, there was no correlation between that visual improvement and time to IAT treatment (fig. 2). In fact, this study demonstrates that patients can make significant visual improvement even when IAT is performed more than $12 \mathrm{~h}$ after symptom onset.

The results of this study seem to directly contradict the current belief that improvement in visual acuity directly correlates with shorter time to thrombolytic therapy $[17-18,20]$. In a recent study by Schmidt et al. [20], 62 patients were evaluated after treatment with IAT and found that patients treated in less than $6 \mathrm{~h}$ were more likely to experience a distinct improvement in visual acuity compared with those treated after $6 \mathrm{~h}(30.77$ vs. $11.13 \%$, respectively). Additionally, other previously published studies have demonstrated a correlation between time to thrombolysis and visual outcomes among patients treated within $6 \mathrm{~h}$ [17-18, 20]. Studies conducted by Weber et al. [18] and Arnold et al. [17] treated patients in 4.2 and $3.68 \mathrm{~h}$ on average, respectively. Both studies demonstrated very positive results. Results from Weber et al. [18] showed that $65 \%$ of patients treated with IAT had at least some improvement in visual acuity compared with only $33 \%$ in the control group. In our study, 26 patients were treated in less than $6 \mathrm{~h}$. Of these 22 patients, a mean visual change of -0.577 logMAR was observed compared with a -0.605 and -0.700 logMAR change in the 6 - to 12 -hour and 12+-hour intervals, respectively. This difference was not found to be significant $(\mathrm{p}=$ 0.72 ).

In our study, the largest improvement in visual acuity occurred in patients treated $12 \mathrm{~h}$ after symptom onset; however, this finding was not statistically significant. Due to the small sample size in the 0 - to 4-hour group, it is impossible to conclude from our study, if patients treated in this time window would have had better visual outcomes compared to other treatment times. It is possible that if a significant amount of data were to be collected on patients treated very early (much less than $4 \mathrm{~h}$ ), it may be possible to see a time effect on 
visual outcomes. Interestingly, Arnold et al. [17] reported that best visual outcomes occurred in patients treated in less than $4 \mathrm{~h}$. Unfortunately, hyper-early time to IAT treatment is difficult to implement and numerous logistical issues exist which are being experienced with current neuroendovascular treatment of large-vessel occlusion AIS.

Nevertheless, our study convincingly demonstrates that while no correlation between time to fibrinolysis and improvement in vision existed at any time point as demonstrated by linear regression $\left(\mathrm{p}=0.99, \mathrm{R}^{2}=0\right.$ for each), visual improvement after IAT was certainly possible within the longer time to treatment windows despite the overall poor prognosis reported for CRAO. It is likely that after some hyper-early time threshold from symptom onset, other factors wield a much greater influence than time on whether an individual patient will improve after IAT therapy. Exploring what these potential influential factors may be should be the focus of future research.

CRAO may manifest as incomplete, subtotal, or total occlusion, and may be differentiated by angiography or fundoscopic findings. Degree of CRAO has been proposed as an important factor in the efficacy of IAT to improve visual outcomes. One study by Ahn et al. [16] demonstrated that patients with incomplete occlusion, compared with total, experienced a significantly higher rate of clinically significant visual improvement, i.e. 76.9 versus $0 \%$, respectively. These results echoed a 2002 study by Schmidt et al. [20] which showed that $50 \%$ of patients who underwent IAT for incomplete occlusion had a distinct improvement in visual acuity compared to $0 \%$ of patients with a total occlusion. Unfortunately, the individual patient data available in our study did not include assessments for the level of occlusion due to limited availability within included studies. Future studies should further examine this correlation and its inclusion in result analysis should always be considered. It is possible with the utilization of fundoscopy, or superselective angiography, that the identification and selective treatment of patients with incomplete or subtotal retinal artery occlusion could lead to the demonstration of the overall efficacy of IAT in future randomized controlled trials irrespective of time to treatment. Establishing the importance of factors such as this could help increase the potential treatment effect of IAT and decrease the sample size necessary for properly powered clinical trials while limiting cases where treatment with IAT is most certainly futile.

The only randomized controlled trial conducted to date concluded that IAT is ineffective in the treatment of CRAO [19]; however, several experts have expressed concerns regarding its validity. Concerns regarding this study have included a severely delayed time to thrombolysis, nonoptimal inclusion/exclusion criteria, and improper methods of blinding [8, 19, 21]. Specifically, important inclusion criteria such as baseline brain imaging and a thorough neurological exam at presentation were not utilized and may have directly influenced study results [21]. In order to prevent these concerns in future studies, further research must be conducted into the most influential factors on outcome after IAT. Our study suggests a less important role for time to thrombolysis in the treatment of CRAO. Additional study into time to treatment may be necessary prior to forcing arbitrary time-to-treatment requirements on the inclusion and exclusion criteria for future randomized controlled trials in the treatment of CRAO.

In addition to questions regarding time to treatment, the vast majority of studies evaluating the use of IAT for CRAO do not provide any method for confirming that recanalization has occurred. Visualization of the central retinal artery during catheter angiography is difficult; therefore, further study into techniques to confirm reperfusion would be beneficial to better define treatment efficacy and minimize the use of thrombolytic agents. Some studies have suggested halting infusion of thrombolytic agents when a rapid improvement of visual acuity occurs or when flow through the retinal and choroidal vessels significantly increase [14]. Fluorescein angiography, as the accepted gold standard for evaluating the retinal circulation, has been utilized in a number of studies as a method of confirming retinal reperfusion 
[16]. Regardless of the method utilized, we recommend future studies to utilize some kind of method of evaluating if recanalization has occurred.

Though our study performed a secondary analysis of actual individual patient data and represents the largest series to evaluate time to IAT treatment for CRAO, limitations to this study exist. As previously mentioned, selection bias and publication bias should always be considered when a large number of uncontrolled outcome studies are utilized for data extraction. However, these biases have minimal influence over the time to treatment data presented here compared to the overall question of whether IAT therapy is efficacious in all CRAO patients. Additionally, the low sample size of patients treated in less than $4 \mathrm{~h}$ is a weakness of this study making it difficult to determine if outcomes are more positive in patients treated in less than $4 \mathrm{~h}$ of symptom onset. This weakness is muted somewhat by the understanding that real-world logistical issues make treatment less than $4 \mathrm{~h}$ after symptom onset difficult and likely impossible for most CRAO patients. Additionally, the exact technique of IAT utilized varied within studies and between studies making direct comparisons difficult. While no obvious correlation between visual outcomes and any specific technique was apparent, we also recommend a formal investigation into the efficacy of the various techniques to better direct future research.

\section{Conclusion}

Acute CRAO is a rare, orphaned disease that has a dismal prognosis with standard noninvasive therapy, and potential advances in treatment have not proven to be efficacious. The impressive visual improvement observed in this series had no relationship to the time from symptom onset to treatment with IAT. This suggests that patients may have the possibility for improvement even with delayed presentation to the neuroendovascular specialist. Other factors, such as completeness of retinal occlusion, may be more important than time to treatment. Additional study to determine optimal patient selection criteria for the endovascular treatment of acute CRAO is needed. Focused attention on very early times to treatment (less than $4 \mathrm{~h}$ ) may be warranted but difficult. In the future, if neuroendovascular treatment of properly selected CRAO patients is found to be efficacious, neuroendovascular specialists should be well positioned to offer this treatment given the recent focus on improving systems of care for the endovascular treatment of large-vessel occlusion AIS.

\section{Disclosure Statement}

The authors report no conflicts of interest.

\section{References}

1 Augsburger JJ, Magargal LE: Visual prognosis following treatment of acute central retinal artery obstruction. Br J Ophthalmol 1980;64:913-917.

2 Atebara NH, Brown GC, Cater J: Efficacy of anterior chamber paracentesis and Carbogen in treating acute nonarteritic central retinal artery occlusion. Ophthalmology 1995;102:2029-2034.

3 Mueller AJ, Neubauer AS, Schaller U, Kampik A: Evaluation of minimally invasive therapies and rationale for a prospective randomized trial to evaluate selective intra-arterial lysis for clinically complete central retinal artery occlusion. Arch Ophthalmol 2003;121:1377-1381.

4 Annonier P, Sahel J, Wenger JJ, Rigolot JC, Foessel M, Bronner A: Local fibrinolytic treatment in occlusions of the central retinal artery. J Fr Ophtalmol 1984;7:711-716. 
5 Chen CS, Lee AW, Campbell B, Lee T, Paine M, Fraser C, Grigg J, Markus R: Efficacy of intravenous tissue-type plasminogen activator in central retinal artery occlusion: report from a randomized, controlled trial. Stroke 2011;42:2229-2234

6 Khatri P, Yeatts SD, Mazighi M, Broderick JP, Liebeskind DS, Demchuk AM, Amarenco P, Carrozzella J, Spilker J, Foster LD, Goyal M, Hill MD, Palesch YY, Jauch EC, Haley EC, Vagal A, Tomsick TA: Time to angiographic reperfusion and clinical outcome after acute ischemic stroke: an analysis of data from the Interventional Management of Stroke (IMS III) phase 3 trial. Lancet Neurol 2014;13:567-574.

7 Hayreh SS, Kolder HE, Weingeist TA: Central retinal artery occlusion and retinal tolerance time. Ophthalmology 1980;87:75-78.

8 Hayreh SS: Comment re: multicenter study of the European Assessment Group for Lysis in the Eye (EAGLE) for the treatment of central retinal artery occlusion: design issues and implications. Graefes Arch Clin Exp Ophthalmol 2007;245:464-466.

9 Lange C, Feltgen N, Junker B, Schulze-Bonsel K, Bach M: Resolving the clinical acuity categories 'hand motion' and 'counting fingers' using the Freiburg Visual Acuity Test (FrACT). Graefes Arch Clin Exp Ophthalmol 2009; 247:137-142.

10 Mercier J, Kastler A, Jean B, Souteyrand G, Chabert E, Claise B, Pereira B, Gabrillargues J: Interest of local intraarterial fibrinolysis in acute central retinal artery occlusion: clinical experience in 16 patients. J Neuroradiol 2015;42:229-235.

11 Pettersen JA, Hill MD, Demchuk AM, Morrish W, Hudon ME, Hu W, Wong J, Barber PA, Buchan AM: Intraarterial thrombolysis for retinal artery occlusion: the Calgary experience. Can J Neurol Sci 2005;32:507-511.

12 Butz B, Strotzer M, Manke C, Roider J, Link J, Lenhart M: Selective intraarterial fibrinolysis of acute central retinal artery occlusion. Acta Radiol 2003;44:680-684.

13 Richard G, Lerche RC, Knospe V, Zeumer H: Treatment of retinal arterial occlusion with local fibrinolysis using recombinant tissue plasminogen activator. Ophthalmology 1999;106:768-773.

14 Schumacher M, Schmidt D, Wakhloo AK: Intra-arterial fibrinolytic therapy in central retinal artery occlusion. Neuroradiology 1993;35:600-605.

15 Framme C, Spiegel D, Roider J, Sachs HG, Lohmann CP, Butz B, Link J, Gabel VP: Central retinal artery occlusion. Importance of selective intra-arterial fibrinolysis. Ophthalmologe 2001;98:725-730.

16 Ahn SJ, Kim JM, Hong JH, Woo SJ, Ahn J, Park KH, Han MK, Jung C: Efficacy and safety of intra-arterial thrombolysis in central retinal artery occlusion. Invest Ophthalmol Vis Sci 2013;54:7746-7755.

17 Arnold M, Koerner U, Remonda L, Nedeltchev K, Mattle HP, Schroth G, Sturzenegger M, Weber J, Koerner F: Comparison of intra-arterial thrombolysis with conventional treatment in patients with acute central retinal artery occlusion. J Neurol Neurosurg Psychiatry 2005;76:196-199.

18 Weber J, Remonda L, Mattle HP, Koerner U, Baumgartner RW, Sturzenegger M, Ozdoba C, Koerner F, Schroth G: Selective intra-arterial fibrinolysis of acute central retinal artery occlusion. Stroke 1998;29:2076-2079.

19 Schumacher M, Schmidt D, Jurklies B, Gall C, Wanke I, Schmoor C, Maier-Lenz H, Solymosi L, Brueckmann H, Neubauer AS, Wolf A, Feltgen N: Central retinal artery occlusion: local intra-arterial fibrinolysis versus conservative treatment, a multicenter randomized trial. Ophthalmology 2010;117:1367-1375.

20 Schmidt DP, Schulte-Monting J, Schumacher M: Prognosis of central retinal artery occlusion: local intraarterial fibrinolysis versus conservative treatment. AJNR Am J Neuroradiol 2002;23:1301-1307.

21 Arthur A, Aaron S: Thrombolysis for artery occlusion. Ophthalmology 2011;118:604-605. 